Vol.02/ No. 04

Pages: 191-200

https://www.irojournals.com/itdw/

DOI: https://doi.org/10.36548/jitdw.2020.4.001

\title{
Tungsten DiSulphide FBG Sensor for Temperature Monitoring in Float Glass Manufacturing
}

\author{
Vince Leona. V, Abirami.M, NirikshaSathianathan, Dr. S. Ponmalar \\ Department of Electronics and Communication Engineering, \\ Thiagarajar College of Engineering, India. \\ Email: \\ vinceleona1234@gmail.com, abimuniysamy1998@gmail.com, niriksha59574@gmail.com, \\ sponmalar1976@gmail.com
}

\begin{abstract}
In this paper, a temperature monitoring system for glass manufacturing process is proposed by using Fibre Bragg Grating (FBG) approach. This system can be done by using OptiSystem simulation. FBG was used as it allows a reflects a wavelength of light that shifts according to variations in temperature. Generally, FBG sensors can be easily installed, it has higher accuracy, longer stability, small in size, immunity to electromagnetic interference (EMI) and the ability to measure ultra-high and speed events. The results indicated that wavelength shifting is depended on thermal expansion coefficient and thermo-optic coefficient of materials, from simulation results it was seen that, Tungsten DiSulfide( $\left(\mathrm{WS}_{2}\right)$ has a better sensitivity than Silica, Poly Methyl Methacrylate(PMMA) and Lead Sulfide(PbS).
\end{abstract}

Keywords - Fibre Bragg Grating sensor; temperature monitoring; glass industry; material comparison; temperature sensitivity.

\section{INTRODUCTION}

In float glass manufacturing process given in Fig1, silica, lime, soda is blended with cullet and heated in a furnace for $1600^{\circ} \mathrm{C}$ to form molten glass. Molten glass is brought down to critical temperature of $1100^{\circ} \mathrm{C}$ after refining and enters the tin bath. Thus float process is the forming operation in industries to work on the glass and form the glass to the shape that we want. Float bath has molten tin which acts as substrate for glass to float over it. Density of tin is $7.3 \mathrm{~kg} / \mathrm{l}$ which is higher than that of the glass of about $2.51 \mathrm{~kg} / \mathrm{l}$ so that it will always remain in top of the substrate. Glass with equilibrium thickness of $5.7 \mathrm{~mm}$ is formed when poured over the molten tin. It can be further stretched/compressed to meet the required thickness.

Flattened glass is taken out of the tin bath around $600^{\circ} \mathrm{C}$ which is done by coolers on downstream of rollers. This is the temperature in which glass is rigid enough to travel on rollers for entering the annealing lehr. Annealing is the slow cooling process in order to relieve the stress created during glass manufacturing. It should take place around $480-540^{\circ} \mathrm{C}$ such that neither the glass enters plastic nor elastic state so that stress can be relieved as well as it will not be broken. Hence temperature monitoring with high sensitivity is mandatory in all these process to ensure the quality of product and to lessen the manufacturing expenses.

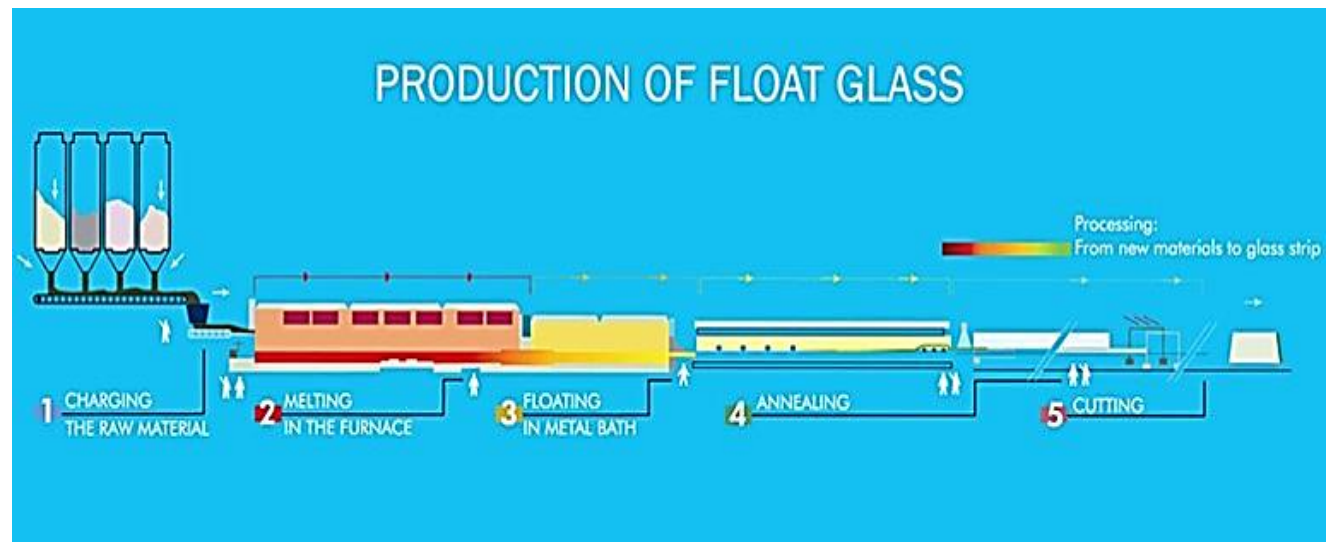

Figure 1: Float Glass Manufacturing Process 
Journal of Information Technology and Digital World (2020)

Vol.02/ No. 04

Pages: 191-200

https://www.irojournals.com/itdw/

DOI: https://doi.org/10.36548/jitdw.2020.4.001

Therefore, in order to monitor temperature with high accuracy we use fibre bragg grating sensors. Fibre based sensors have been widely applied in the measurement of these physical parameters where the information is encoded by the Bragg wavelength shift. Many Fibre Bragg Grating can be integrated on a Single Mode Fibre(SMF) to detect temperature/strain changes at that point [1] and also have shift in Bragg wavelength when there is in deviation in temperature [2]. In our paper we are using FBG for monitoring temperature at various process of glass industry, namely in furnace, tin bath and in annealing lehr. Various materials such as Graphene Oxide, Aluminium Oxide, Tungsten DiSulfide, Lead Sulfide, Molybdenum Disulfide etc. can be doped onto SMF to enhance the sensitivity of pure Silica Fibre Bragg Grating sensor due to changes in the physical parameters of these materials. PMMA results in higher sensitivity but the operating range is limited around $105^{\circ} \mathrm{C}$ [4]. Lead Sulfide and Tungsten Disulfide have good optical properties which results in high operating temperature range along with better sensitivity [3][5].

\section{FBG PRINCIPLE}

A Fibre Bragg Grating is basically a spatial variation of the refractive index inside the core of an optical fibre. This change in the refractive index further causes a shift in the Bragg wavelength. As a result, it tends to act as a stop band filter. This phenomenon was first observed by Ken Hill in 1978. When light from a broadband source is launched from one side of the fibre, only a particular wavelength which satisfies Bragg condition will be reflected while the remainder is transmitted without any loss. Periodic RI variations reflect the incoming wave front and constructively form a back reflected power peaked at a centre wavelength defined by the grating characteristics. The reflected wavelength with maximum efficiency is called the Bragg wavelength. This can be observed from Fig 2(optical fibre containing the Bragg grating which is indicated as black strips in the core of the fibre. The input spectra along with its corresponding reflection and transmission spectrum are also shown-).

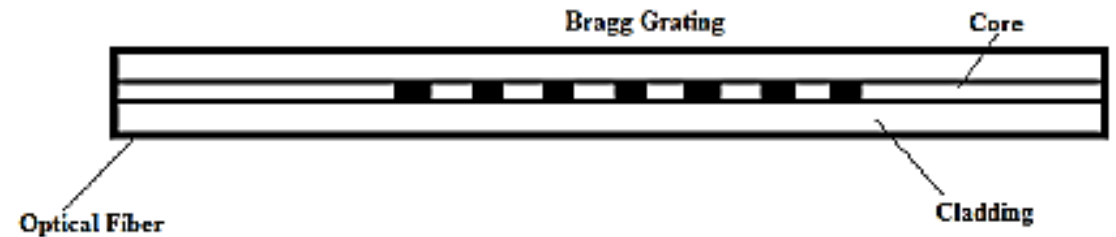

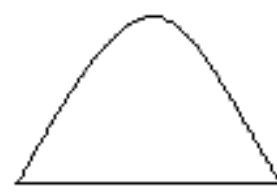

Input Sigual

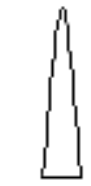

Reflected Sigual

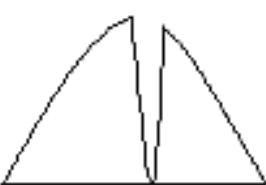

Transmitted Signal

Figure 2: FBG Principle

The Bragg reflected wavelength is given by

$$
\lambda \mathrm{B}=2 \mathrm{n} \Lambda
$$

where ' $\lambda \mathrm{B}$ ' is the Bragg wavelength, ' $\mathrm{n}$ ' denotes the effective index of the core and ' $\Lambda$ ' is the spacing between the gratings. This equation indicates that the shift in Bragg wavelength results from the change of the two parameters which are effective refractive index and grating period which is caused by a change in the physical parameters such as temperature or strain. Any parameter that has the ability to affect either the refractive index or the grating period can be measured using an FBG as a sensor. The change in the parameter will correspond to a change in the peak reflected wavelength.

In this paper we consider the wavelength variations with temperature

$\Delta \lambda / \lambda=(\alpha+\tau) * \Delta \mathrm{T}$

where ' $\Delta \lambda$ ' is the wavelength shift when there is a change in temperature, ' $\lambda \mathrm{B}$ ' is the Bragg wavelength, ' $\alpha$ ' is the thermal expansion coefficient, ' $\tau$ ' is the thermo optic coefficient and ' $\Delta \mathrm{T}$ ' is the change in temperature.

Information Technology

Digital World 
Journal of Information Technology and Digital World (2020)

Vol.02/ No. 04

Pages: 191-200

https://www.irojournals.com/itdw/

DOI: https://doi.org/10.36548/jitdw.2020.4.001

\section{DESIGN}

OptiSystem software is used to design and simulate the Fibre Bragg Grating sensor system for monitoring temperature at three critical steps of float glass manufacturing process. The system consists of white light source and three Uniform Fibre Bragg Grating designed with Bragg centre wavelength of $1545 \mathrm{~nm}, 1550 \mathrm{~nm}$ and 1554 $\mathrm{nm}$ at reference temperature of $1100^{\circ} \mathrm{C}, 600^{\circ} \mathrm{C}$ and $490^{\circ} \mathrm{C}$ as a reference temperature in the range $\left(480^{\circ} \mathrm{C}-540^{\circ} \mathrm{C}\right)$ respectively which in turn connected to the Optical Spectrum Analyser via power combiner or coupler to view the reflected spectrum as shown in Fig 3 and Fig 4 respectively as well as transmission spectrum can also be viewed with OSA.

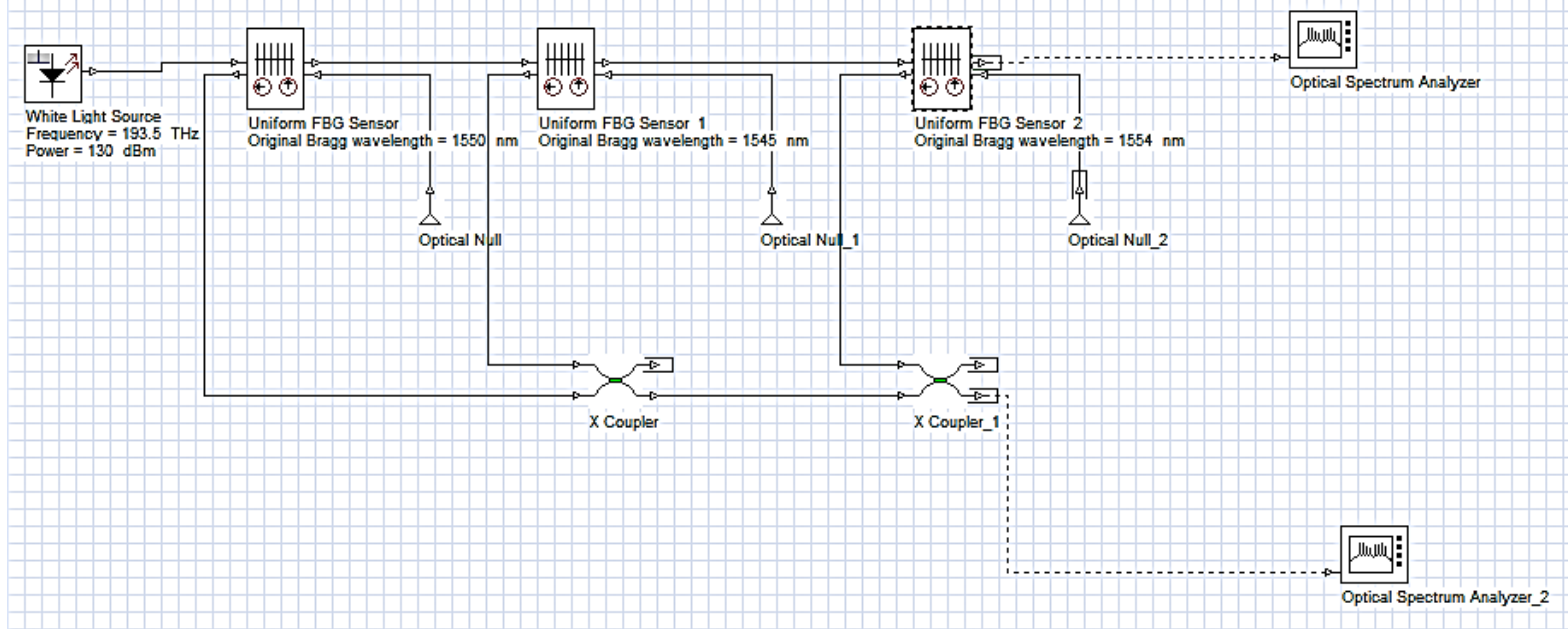

Figure 3 Block diagram of Fibre Bragg Grating Sensor Array using Coupler

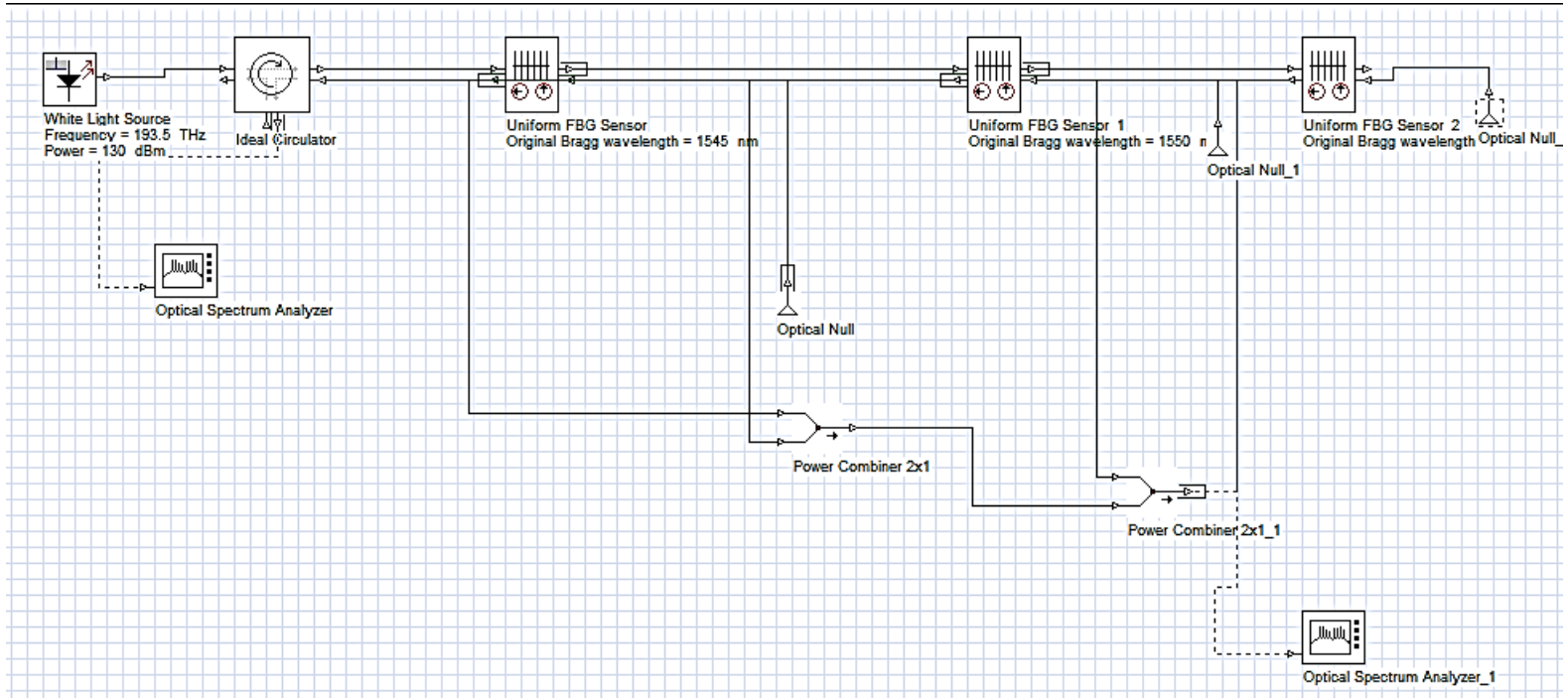

Figure 4 Block diagram of Fibre Bragg Grating Sensor Array using Power Combiner

Transmission and reflection spectrum of FBGat set reference temperature is viewed by OSA. Transmission spectrum has the least power and reflection spectrum has the maximum power at the designed Bragg wavelength. Bragg Wavelength shift due to temperature change depends on refractive index, thermo-optic coefficient and thermalexpansion coefficient of the material used to fabricate the FBG. Thus comparison of Silica, PMMA, Tungsten Disulfide and Lead Sulfidewith different characteristics is made to achieve higher sensitivity as shown in Table1.

Information Technology \&

Digital World 
Journal of Information Technology and Digital World (2020)

Vol.02/ No. 04

Pages: 191-200

https://www.irojournals.com/itdw/

DOI: https://doi.org/10.36548/jitdw.2020.4.001

Table 1 Comparison of Silica, PMMA, PbS and WS2

\begin{tabular}{|c|c|c|c|}
\hline Material & $\begin{array}{c}\text { Effective refractive } \\
\text { index }\end{array}$ & $\begin{array}{c}\text { Thermo-optic } \\
\text { coefficient }\end{array}$ & $\begin{array}{c}\text { Thermal expansion } \\
\text { coefficient }\end{array}$ \\
\hline Silica & 1.45 & $8.6 \mathrm{E}-6$ & $0.55 \mathrm{E}-6$ \\
\hline PMMA & 1.49 & $-127 \mathrm{E}-6$ & $70 \mathrm{E}-6$ \\
\hline $\begin{array}{c}\text { Tungsten } \\
\text { Disulfide(WS2) }\end{array}$ & $4.1462+\mathrm{i} 0.699$ & $3.36 \mathrm{E}-04$ & $7.5 \mathrm{E}-06$ \\
\hline $\begin{array}{c}\text { Lead Sulfide(PbS) } \\
\text { Pus }\end{array}$ & 3.91 & $1.23 \mathrm{E}-05$ & $6.3 \mathrm{E}-07$ \\
\hline
\end{tabular}

By changing these parameters, comparison is made for all these materials, simulated and performance is observed.

\section{RESULTS}

On varying the characteristics in the component properties of Uniform Fibre Bragg Grating, simulation of different materials as discussed above can be obtained. With pure Silica FBG temperature sensitivity of $0.01 \mathrm{~nm} /{ }^{\circ} \mathrm{C}$ is obtained. Though Silica being easily available material and does not need any doping, small shift in Bragg wavelength could not be detected easily through naked eye. Fig 5 and Fig 6 shows the reflection spectrum for deviation of $\pm 1^{\circ} \mathrm{C}$ and zoomed spectrum to infer the shift for research purpose.

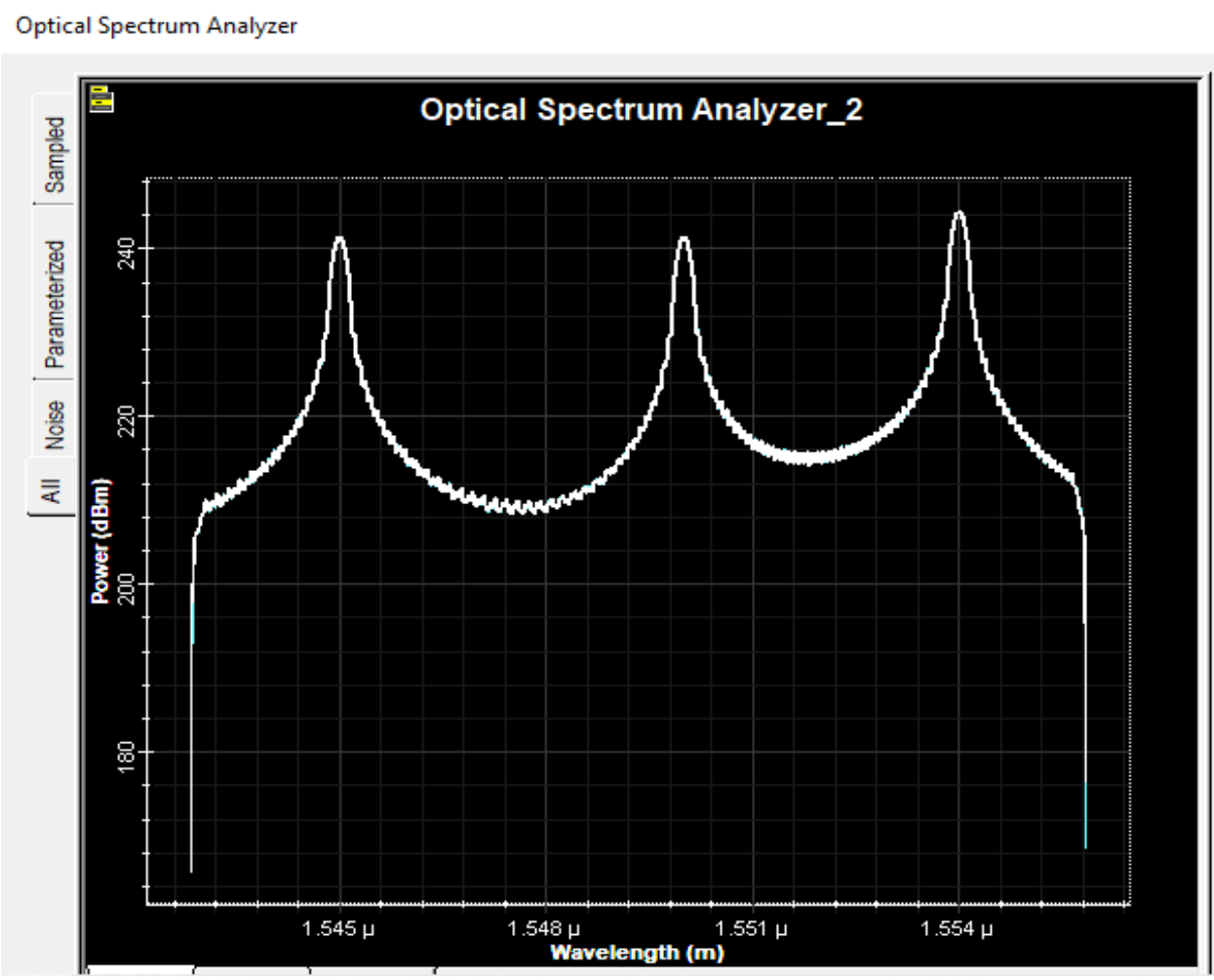

Figure: 5 Bragg Wavelength shift of Silica $\mathrm{FBG}$ for $\pm 1^{\circ} \mathrm{C}$ fromreference temperature 
Journal of Information Technology and Digital World (2020)

Vol.02/ No. 04

Pages: 191-200

https://www.irojournals.com/itdw/

DOI: https://doi.org/10.36548/jitdw.2020.4.001

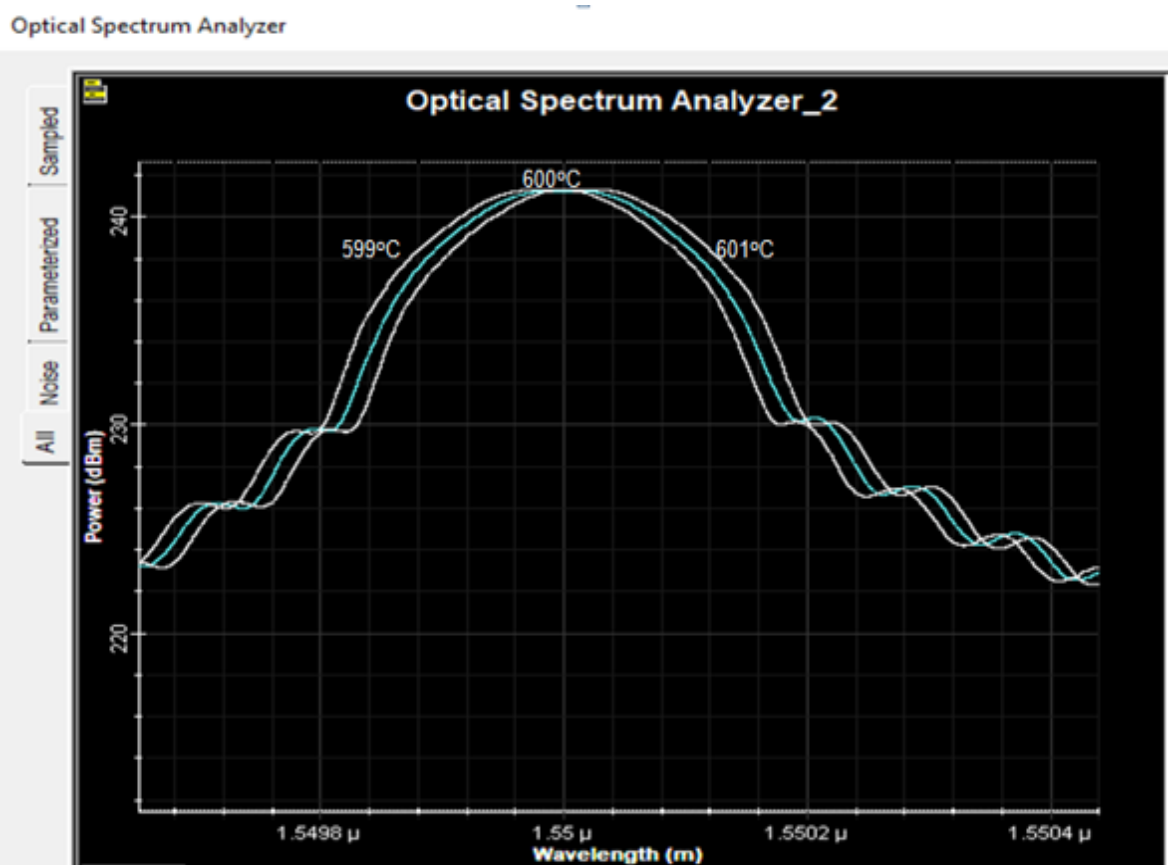

Figure: 6 (Zoomed view) Bragg Wavelength shift of Silica FBG for $\pm 1^{\circ} \mathrm{C}$ fromreference temperature

Poly Methyl Methacrylate doped Fibre Bragg Grating leads to sensitivity of $0.07 \mathrm{~nm} /{ }^{\circ} \mathrm{C}$ which is easily viewable and detectable, melting point of PMMA is $105^{\circ} \mathrm{C}$ and thus operating range is limited which is very much less than operating temperature on glass industries. Fig 7 depicts the reflection spectrum of PMMA doped FBG for shift of $\pm 1^{\circ} \mathrm{C}$.

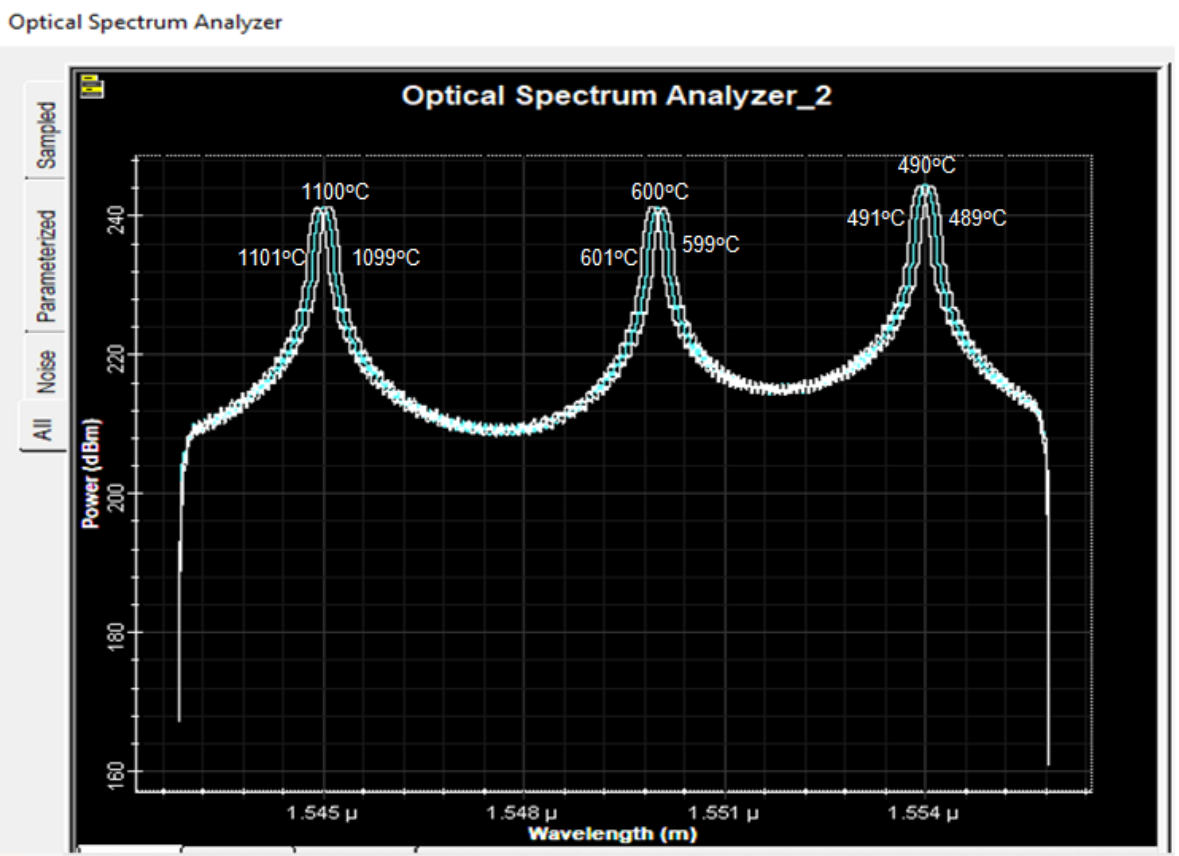

Figure 7 Bragg Wavelength shift of PMMA FBG for $\pm 1^{\circ} \mathrm{C}$ from reference temperature

From Lead Sulfide doped FBG sensor temperature sensitivity of $0.02 \mathrm{~nm} /{ }^{\circ} \mathrm{C}$ is obtained which is lesser than that of PMMA but suitable for glass industry with high operating temperature range. Fig 8 and Fig 9 shows the reflected spectrum for the shift of $\pm 1^{\circ} \mathrm{C}$ and zoomed view for better understanding respectively. 
Journal of Information Technology and Digital World (2020)

Vol.02/ No. 04

Pages: 191-200

https://www.irojournals.com/itdw/

DOI: https://doi.org/10.36548/jitdw.2020.4.001

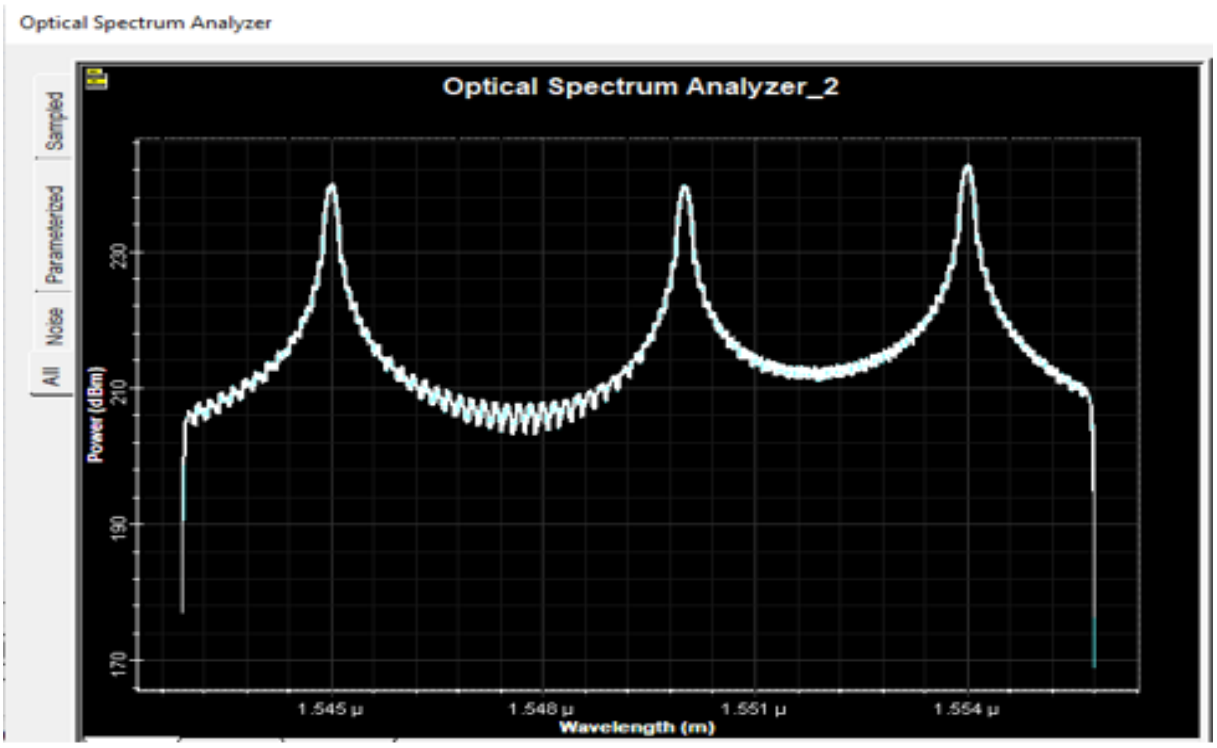

Figure 8 Bragg Wavelength shift of $\mathrm{PbS}$ FBG for $\pm 1^{\circ} \mathrm{C}$ from reference temperature

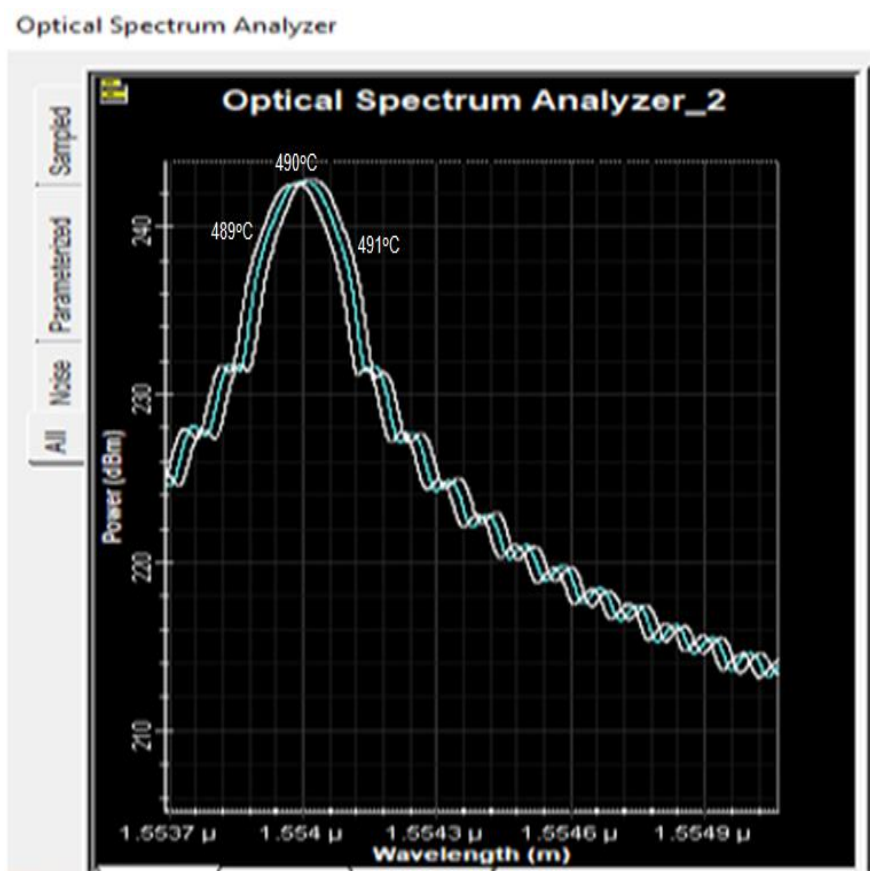

Figure 9 (Zoomed view) Bragg Wavelength shift of $\mathrm{PbS}$ FBG for $\pm 1^{\circ} \mathrm{C}$ from reference temperature

Tungsten DiSulfide doped Fibre Bragg Grating sensor results in higher sensitivity of $0.5 \mathrm{~nm} /{ }^{\circ} \mathrm{C}$ as well as wider operating range which is much suitable for float glass manufacturing process. Fig 10 depicts reflected spectrum for the shift of $\pm 1^{\circ} \mathrm{C}$. 
Journal of Information Technology and Digital World (2020)

Vol.02/ No. 04

Pages: 191-200

https://www.irojournals.com/itdw/

DOI: https://doi.org/10.36548/jitdw.2020.4.001

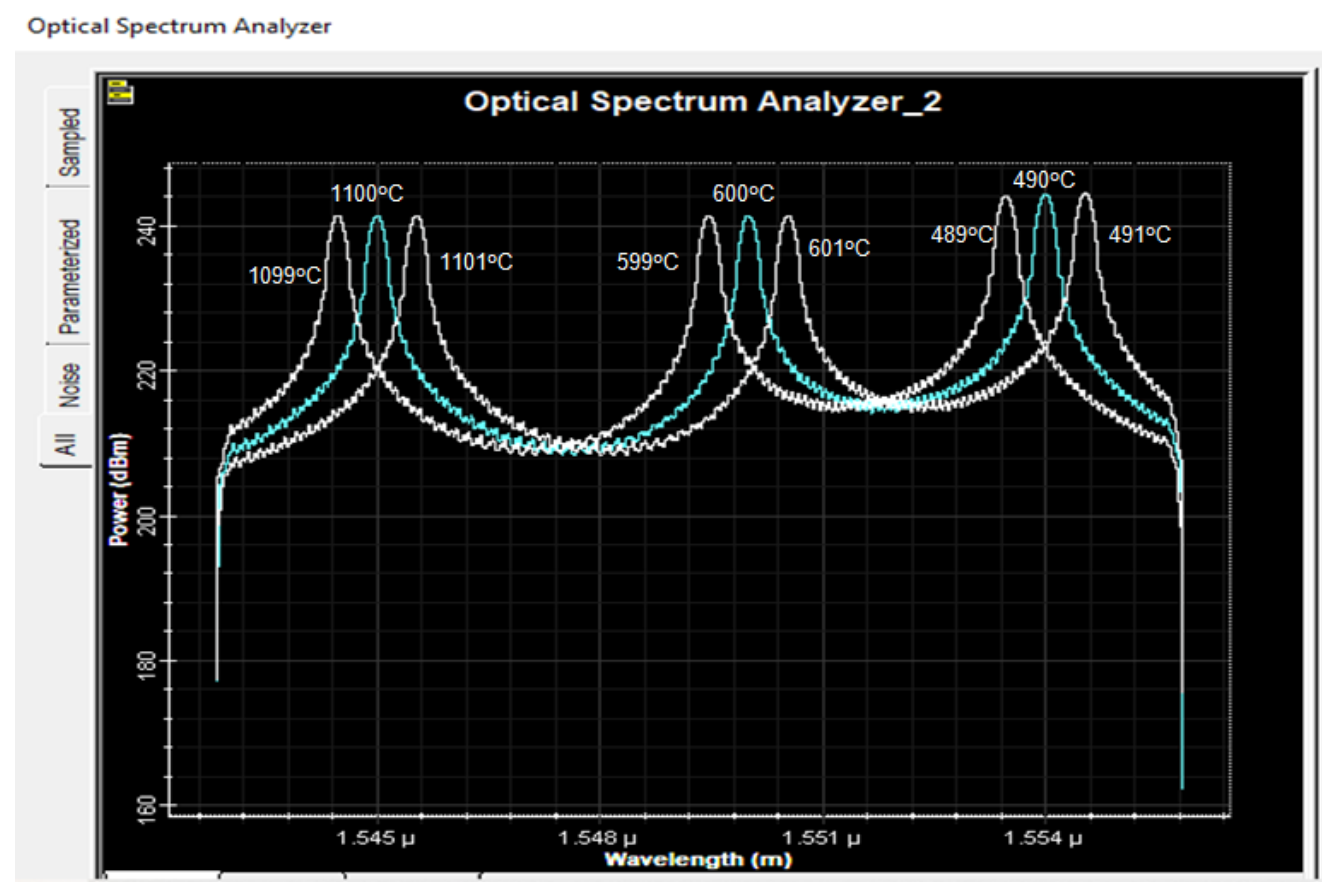

Figure 10 Bragg Wavelength shift of WS2 FBG for $\pm 1^{\circ} \mathrm{C}$ fromreference temperature

According to the formula (2) stated above, temperature sensitivity calculated for each FBG sensor is as shown in Table (2) which is similar to that of the results obtained in our simulation.

Table 2: Temperature Sensitivity Comparison

\begin{tabular}{|c|c|}
\hline Material & Temperature Sensitivity $/{ }^{\circ} \mathbf{C}$ \\
\hline Silica & $0.01 \mathrm{~nm}$ \\
\hline $\mathrm{PbS}$ & $0.02 \mathrm{~nm}$ \\
\hline $\mathrm{PMMA}$ & $0.07 \mathrm{~nm}$ \\
\hline $\mathrm{WS}_{2}$ & $0.50 \mathrm{~nm}$ \\
\hline
\end{tabular}

As the temperature increases or decreases the Bragg wavelength shift towards right or left respectively in Silica, Lead Sulphide and Tungsten Disulfide because of its positive thermo optic co-efficient whereas in PMMA as the temperature increases/decreases the Bragg wavelength sift towards left/right respectively because of its negative thermo optic co-efficient at all operating temperature range which could be clearly inferred from Fig 11, Fig 12 and Fig 13. 
Journal of Information Technology and Digital World (2020)

Vol.02/ No. 04

Pages: 191-200

https://www.irojournals.com/itdw/

DOI: https://doi.org/10.36548/jitdw.2020.4.001

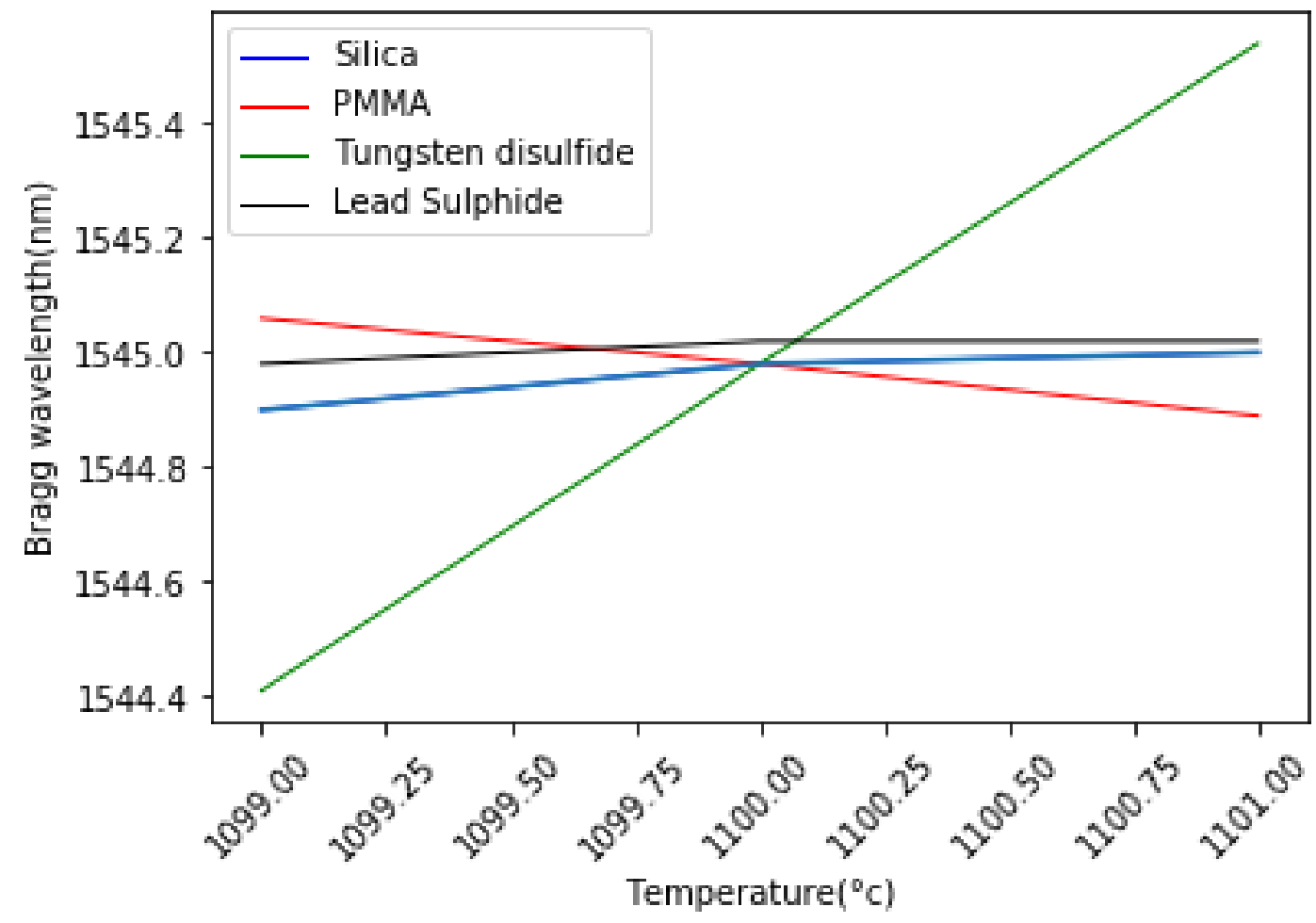

Figure 11 Relation between Temperature and Bragg wavelength at reference temperature of $1100^{\circ} \mathrm{C}$

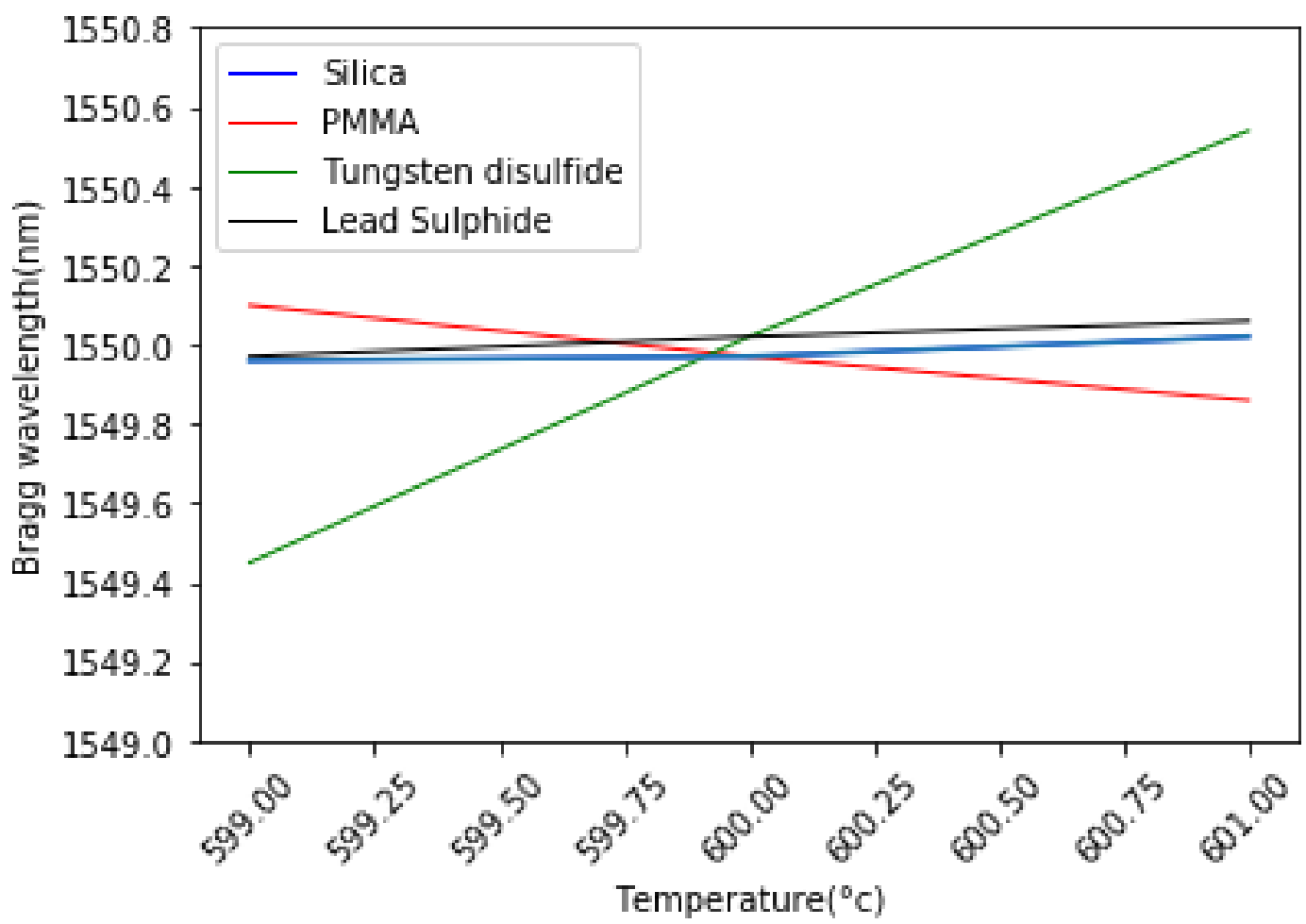

Figure 12 Relation between Temperature and Bragg wavelength at reference temperature of $600^{\circ} \mathrm{C}$ 
Journal of Information Technology and Digital World (2020)

Vol.02/ No. 04

Pages: 191-200

https://www.irojournals.com/itdw/

DOI: https://doi.org/10.36548/jitdw.2020.4.001

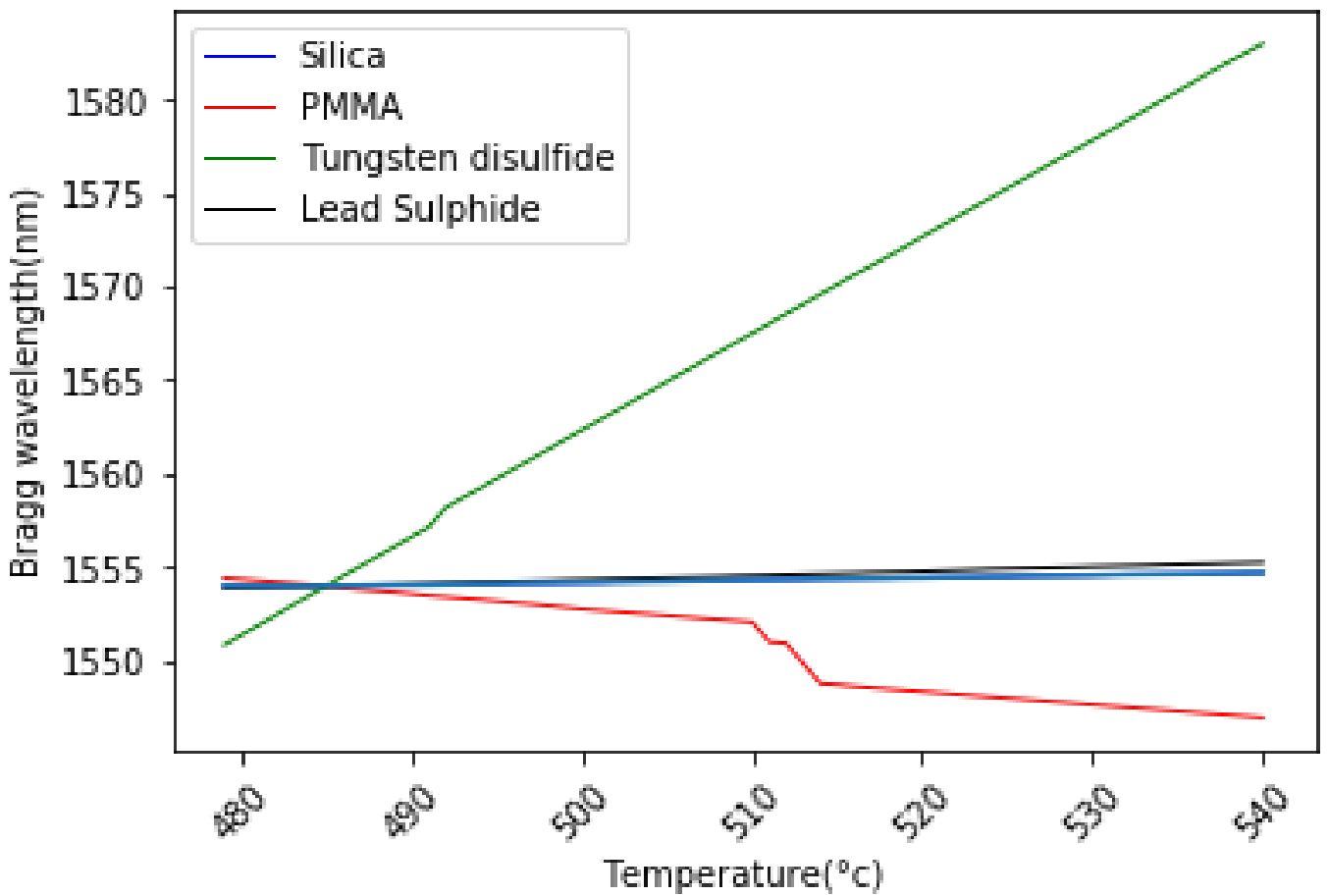

Figure 13 Relation between Temperature and Bragg wavelength at reference temperature of $480^{\circ} \mathrm{C}-540^{\circ} \mathrm{C}$

\subsection{DISCUSSIONS}

From the simulation results obtained for various materials, Tungsten DiSulfide showed better performance. Wavelength shift corresponding to critical situations can be found from lookup table (Table 3, Table4, Table 5) provided below and the process can be continued without interruption on resetting the temperature within few seconds.

Table 3 (Lookup Table)

Position: Fibre Bragg Grating before the float bath

Reference Temperature: $1100^{\circ} \mathrm{C}$

\begin{tabular}{|l|l|l|}
\hline Bragg Wavelength $(\mathbf{n m})$ & Wavelength shift $(\mathbf{n m})$ & Condition \\
\hline \multirow{2}{*}{1545} & 1544.98 & Normal \\
\cline { 2 - 3 } & $>1544.98$ or $<1544.98$ & Threat \\
\hline
\end{tabular}

Table 4 (Lookup Table)

Position: Fibre Bragg Grating after the float bath

Reference Temperature: $600^{\circ} \mathrm{C}$

\begin{tabular}{|l|l|l|}
\hline Bragg Wavelength(nm) & Wavelength shift $(\mathbf{n m})$ & Condition \\
\hline \multirow{2}{*}{1550} & 1550.02 & Normal \\
\cline { 2 - 3 } & $>1550.02$ or $<1550.02$ & Threat \\
\hline
\end{tabular}

Table 5 (Lookup Table)

Position: Fibre Bragg Grating in annealing lehr

Reference Temperature: $480-540^{\circ} \mathrm{C}$

\begin{tabular}{|l|l|l|}
\hline Bragg Wavelength(nm) & Wavelength shift $(\mathbf{n m})$ & Condition \\
\hline \multirow{2}{*}{1554} & 1554.01 & Normal \\
\cline { 2 - 3 } & $<1550.85$ or $>1583.01$ & Threat \\
\hline
\end{tabular}


Journal of Information Technology and Digital World (2020)

Vol.02/ No. 04

Pages: 191-200

https://www.irojournals.com/itdw/

DOI: https://doi.org/10.36548/jitdw.2020.4.001

\section{CONCLUSION}

Fibre Bragg Grating Sensor offers direct absolute measurement compare to conventional electric and alternative fibre sensors as well asnon-conductive, electrically passive and immune to EMI induced noise. They can detect temperature deviation in picoseconds which is much lesser than existing systems in glass industries. In conclusion, Tungsten DiSulfide doped Fibre Bragg Grating sensor with sensitivity of $0.5 \mathrm{~nm} /{ }^{\circ} \mathrm{C}$ and melting point of $1250^{\circ} \mathrm{C}$ is suitable for continuous temperature monitoring in harsh environment of float glass manufacturing process.

\section{REFERENCES}

[1] UgisSenkans, Janis Braunfelds, Ilya Lyashuk, JurgisPorins, SandisSpolitis and VjaceslavsBobrovs. "Research on FBG-Based Sensor Networks and Their Coexistence with Fibre Optical Transmission Systems", Journal of Sensors, Volume 2019.

[2] Anania S, Anjali Unnikrishnan, Aparna A, Parvathi G R, Baby Sreeja.S.D and Poornima Mohan. "Analytical study of fbg spectrum for temperature sensing applications", 2nd International Conference on Inventive Communication and Computational Technologies (ICICCT 2018).

[3] Xiangping Pan, Yanhua Dong, Jiajia Zheng, Jianxiang Wen, Member, IEEE, Fufei Pang, Member, IEEE,Zhenyi Chen, Member, IEEE, Yana Shang and Tingyun Wang, Member, IEEE. "Enhanced FBG Temperature Sensitivity in PbS-doped Silica Optical Fiber”,Journal of Lightwave Technology,2019.

[4] Wei Zhang, David J. Webb and Gang-Ding Peng, Aston Institute of Photonic Technologies UK, School of Electrical Engineering and Telecommunications, University of New South Wales Australia. "Enhancing the sensitivity of poly(methyl methacrylate) based optical fiber Bragg grating temperature sensors", Optics Letter Volume 40,2015.

[5] Kan Wu, Yifang Wang, CiyuanQiu and Jianping Chen State Key Laboratory of Advanced Optical Communication Systems and Networks, Department of Electronic Engineering, Shanghai Jiao Tong University, Shanghai China. "Thermo-optic all-optical devices based on two-dimensional materials", Vol. 6, No. 10 / October 2018 / Photonics Research.

[6] Guo-Hui Lv, Shao-Hua Shang, Xu Jiang, Jin-Ping Ou, Chao Yang, Chuan-Di Li, and Wei Xu. "FBG Temperature and Pressure Sensing System for Hot Water Pipeline of Petrochemical Factory",APOS2008.

Information Technology

\&

Digital World 